\title{
Local deformation behavior of surface porous polyether-ether-ketone
}

Nathan T. Evans ${ }^{*}{ }^{*}$, F. Brennan Torstrick ${ }^{\mathrm{b}}$, David L. Safranski ${ }^{\mathrm{c}}$, Robert. E. Guldberg ${ }^{\mathrm{b}}$, Ken Gall ${ }^{\mathrm{d}}$

${ }^{a}$ School of Materials Science and Engineering, Georgia Institute of Technology, 771 Ferst Drive,

J. Erskine Love Building, Atlanta, GA 30332

${ }^{\mathrm{b}}$ School of Mechanical Engineering, Georgia Institute of Technology, 801 Ferst Drive, Atlanta, GA 30332

${ }^{\mathrm{c}}$ MedShape, Inc., 1575 Northside Drive, NW, Suite 440, Atlanta, GA 30318, USA

${ }^{\mathrm{d}}$ Department of Mechanical Engineering and Materials Science, Duke University, Box 90300

Hudson Hall, Durham, NC 27708-0287

*Corresponding Author

\section{Contact Information:}

Evans: nevans3@gatech.edu 404-660-4418

Torstrick: brennan@gatech.edu

Safranski: david.safranski@medshape.com

Guldberg: robert.guldberg@me.gatech.edu

Gall: ken.gall@duke.edu

Keywords: polyether-ether-ketone, porous, compression, microcomputed tomography, wear 


\begin{abstract}
Surface porous polyether-ether-ketone has the ability to maintain the tensile monotonic and cyclic strength necessary for many load bearing orthopedic applications while providing a surface that facilitates bone ingrowth; however, the relevant deformation behavior of the pore architecture in response to various loading conditions is not yet fully characterized or understood. The focus of this study was to examine the compressive and wear behavior of the surface porous architecture using micro Computed Tomography (micro CT). Pore architectures of various depths $(\sim 0.5-2.5 \mathrm{~mm})$ and pore sizes $(212-508 \mu \mathrm{m})$ were manufactured using a melt extrusion and porogen leaching process. Compression testing revealed that the pore architecture deforms in the typical three staged linear elastic, plastic, and densification stages characteristic of porous materials. There was no effect of pore size and all experimental moduli and yield strengths decreased with increasing porosity and agreed well with foam theory. The experimental moduli and yield strengths decreased as the porosity increased but there was no difference in properties between pore sizes. The porous architecture maintained a high degree of porosity available for bone-ingrowth at all strains. Surface porous samples showed no increase in wear rate compared to injection molded samples, with slight pore densification accompanying wear.
\end{abstract}

\title{
1. Introduction
}

Surface porous polyether-ether-ketone (PEEK) has recently emerged as a candidate material for load bearing in orthopedic applications due to its favorable bulk mechanical properties, imaging compatibility, and promising in vitro and in vivo results [1-3]. Prior studies have investigated the tensile and fatigue properties of PEEK containing a surface porous architecture, but the local deformation response of the porous region itself has not been previously explored. 
The evaluation of the local compressive properties of surface porous PEEK is important as most implants are subject to compressive loading in vivo. For example, the human spine is subjected to large compressive loads during daily activities. During standing or walking compressive loads can reach $1000 \mathrm{~N}$ [4] and activities such as lifting further increase these loads $[5,6]$. After interbody fusion of the spine, loads can be partially transferred through an interbody fusion device until the space is bridged with new bone. In the knee, biomechanical studies of the joint during loading have consistently estimated maximum joint compressive forces to be about 4 to 4.5 times bodyweight during daily activities but can be as high as 8 times bodyweight during downhill walking [7]. Because the tibiofemoral contact area of most total knee replacement designs is 100 to $300 \mathrm{~mm}^{2}$ [7], these implants are subjected to high stress states. From these two examples, it is clear that careful consideration of the compressive properties of the porous architecture must be undertaken to understand how the material might perform clinically.

In addition to deformation resulting from compressive loading, it is critical to study the abrasion resistance of surface porous PEEK. Even in non-articulating applications, micromotion at the bone-implant interface can cause the formation of wear debris, which can potentially lead to an inflammatory response and bone resorption [8, 9]. A relevant ASTM standard highlights that particle shedding might occur during surgical insertion of an implant or as the result of micromotion of the implant after insertion [10]. The favorable wear properties of PEEK and its composites have led to its investigations as a bearing material in joint replacements, particularly as a replacement for ultra-high molecular weight polyethylene (UHMWPE) [11]. Most studies have considered the use of carbon fiber reinforced (CFR) PEEK due to its superior wear resistance compared to neat PEEK. Studies have shown that the CFR-PEEK offers a far superior wear resistance over UHMWPE against either metal or ceramic couples [12]. Work investigating 
use of a CFR-PEEK acetabular cup against alumina femoral heads demonstrated that such wear couples approach the bearing performance of hard-on-hard, such as metal-on-metal, surfaces [13]. A thorough examination has also been given to the bioactivity of wear particles produced from PEEK devices. Multiple studies evaluated the cytotoxicity of wear debris from CFR-PEEK devices in vitro and found no cytotoxic or mutagenic potential $[14,15]$. The in vivo response has also been characterized. CFR-PEEK wear particles injected into the knees of mice showed comparable biological activity to UHMWPE particles [16] and PEEK particles injected into the spinal canal of rabbits demonstrated neither necrosis nor swelling of the dura mater and nerve roots [17].

Despite the low risk of PEEK debris, it is nevertheless important to consider the abrasion resistance of surface porous PEEK. It is typical that porosity is detrimental to the wear resistance of materials, though some experiments show exceptions [18]. Porosity increases the surface roughness of materials, decreases the real area of contact between two sliding surfaces, and consequently increases the contact pressure which promotes material removal during sliding [19]. The wear rate has been shown to increase with increasing porosity and consequently the goal of many coatings is to minimize the porosity present $[20,21]$. It is therefore important to evaluate the abrasion resistance of surface porous PEEK compared to currently used injection molded PEEK surfaces.

The overall focus of this work is to study the mechanics of the porous architecture relevant to orthopedic applications. Compression testing provided understanding of the strength and stiffness of the porous architecture decoupled from the underlying solid PEEK.

Microcomputed tomography scans $(\mu \mathrm{CT})$ of the surface porous architecture at various compressed states were used to understand the pore architecture deformation mechanisms. The 
$\mu \mathrm{CT}$ studies revealed the elastic, plastic, and densification deformation stages with increasing compression, consistent with previous experimental results [22] and numerical simulations of polymer foams [23]. Abrasion testing demonstrated that the wear rate of surface porous PEEK is not higher than injection molded PEEK due to a difference in wear mechanism.

\section{Experimental Methods}

\subsection{Materials}

Medical grade polyetheretherketone (PEEK Zeniva ${ }^{\circledR} 500$ ) was provided by Solvay Advanced Polymers (Alpharetta, GA). Sodium chloride crystals were purchased from Sigma Aldrich (St. Louis, MO).

\subsection{Sample preparation}

Surface porous PEEK was created by extruding the polymer samples through the open spacing of sodium chloride crystals under heat and pressure as described previously [1]. To control for pore size, sodium chloride was sieved into ranges of 200-312 $\mu \mathrm{m}, 312-425 \mu \mathrm{m}$, and 425-508 $\mu \mathrm{m}$ using \#70, \#50, \#40, and \#35 U.S. mesh sieves. Surface porous (SP) samples processed using each size range are referenced as SP-250, SP-350, and SP-450, respectively. To control the pore architecture depth, the PEEK was extruded through the sodium chloride either $0.65 \mathrm{~mm}$ or $1.5 \mathrm{~mm}$ to create "thin" and "thick" samples, respectively.

Cylindrical samples of approximately $16 \mathrm{~mm}$ diameter x $16 \mathrm{~mm}$ height with a surface porous architecture were prepared for compression testing. The total sample height remained constant at $16 \mathrm{~mm}$ (i.e. the thickness of the solid plus the depth of the pore architecture equaled approximately $16 \mathrm{~mm}$ ). The diameter and height of each sample was measured using digital 
calipers immediately prior to testing and all samples were scanned using $\mu \mathrm{CT}$ to determine the percent porosity and the pore depth.

Abrasion samples were prepared by processing a surface porous architecture on $10 \mathrm{~cm} \mathrm{x}$ $10 \mathrm{~cm} \mathrm{x} 4 \mathrm{~mm}$ thick plaques. All three pore sizes were processed and all abrasion samples had “thin" pore architectures. Following processing, a $6.4 \mathrm{~mm}$ diameter hole was drilled to allow attachment to the Taber Rotary Abraser (Taber Industries; North Tonawanda, NY).

\subsection{Pore morphometry characterization}

Surface porous samples were evaluated using micro-computed tomography ( $\mu \mathrm{CT} 50$; Scanco Medical, Wayne, PA) at $10 \mu \mathrm{m}$ voxel resolution with the scanner set at a voltage of 55 $\mathrm{kVp}$ and a current of $200 \mu \mathrm{A}(\mathrm{n}=8)$. A global threshold was applied to segment PEEK from pore space for all evaluations. Pore architecture morphometric parameters were evaluated using direct distance transformation methods as described previously [1, 24].

\subsection{Compression testing}

Compression tests were utilized to determine the compressive stress- strain behavior of surface porous PEEK. The tests were performed using an Instron machine with a $5 \mathrm{kN}$ load cell at room temperature (Instron; Norwood, MA). The samples were compressed past yield of the solid component using a displacement controlled test at a rate of $1.3 \mathrm{~mm} / \mathrm{min}$ according to ASTM D695-10 [10].

To understand the mechanical properties of the pore architecture, the stress-strain response of the surface porous PEEK and solid PEEK were decoupled. To do so, the stress-strain response of solid PEEK cylinders $(16 \mathrm{~mm} x 16 \mathrm{~mm})$ was measured $(\mathrm{n}=3)$. We then made the following two assumptions: (1) the force throughout the samples is uniform (i.e. the force in the porous architecture is the same as that in the solid) and (2) at a given force, the strain in the solid 
region of surface porous samples is the same as in the solid sample alone. Based on these assumptions, we subtracted out the strain (and subsequently the displacement using the pore depth data from $\mu \mathrm{CT})$ of the solid region from the SP samples $(\mathrm{n}=3)$ leaving only the displacement-force data for the surface porous architecture. The elastic modulus was then calculated for each material as the slope of by drawing a tangent to the initial linear (Hookean) portion of each stress-strain curve and dividing the compressive stress represented by this point by the corresponding strain. In addition the toe region was compensated for to give the correct zero point on the strain axis by continuing the linear (Hookean) region through the zero-stress axis and using this intersection as the corrected zero-strain point and the yield using a toe eørrection.

\subsection{In situ $\mu$ CT compression}

To evaluate the pore morphometry as a function of stress and strain, a Scanco Medical Compression/Tension Device was used together with the Scanco Medical $\mu$ CT 50. Samples were placed under a small preload ( $2 \mathrm{~N}, 0 \%$ strain condition) to prevent rotation during scanning and then were scanned as described above. The compression device was then used to compress the sample to $5 \%$ strain. The samples were then rescanned and compressed to another $5 \%$ strain of the original height. This process was continued in $10 \%$ strain increments until the sample was compressed to $70 \%$ of the original height. Pore architecture morphometrics were determined as described previously. Displacement control was used throughout the tests to control the strain and slight stress relaxation occurred during the duration of the scans. The 350 pore size was used and three samples were tested for both pore architecture depths.

\subsection{Taber abrasion test}


The abrasion resistance of the porous architecture was characterized according to ASTMF1978. This test method provides a means to evaluate the resistance to particle shedding of a thermal spray coating but has been adapted for the surface porous technology studied here. In short, samples $10 \mathrm{~cm} \times 10 \mathrm{~cm} \times 4 \mathrm{~mm}$ thick with a $6.4 \mathrm{~mm}$ hole $(\mathrm{n}=8 \mathrm{SP}-350, \mathrm{n}=3$ all other samples) were placed on a Taber Rotary Abraser Model 5135 (Taber Industries; North Tonawanda, NY) with H22 Calibrade wheels and a load of 250g. The samples were placed in such a way that the pore architecture was face up with the surface porous architecture in contact with the ceramic wheels so that the surface under abrasion was the porous architecture; the solid material was not exposed to abrasion in the surface porous samples. The samples were abraded for $2,5,10$, and 100 cycles with the vacuum on. Between each abrasion cycle the samples were cleaned in an ultrasonic cleaner for at least 20 minutes, dried in a vacuum oven at $100^{\circ} \mathrm{C}$ for 1 hour and then cooled at room temperature for 10 minutes. The samples were then weighed 3

times. The clean, dry, and weigh cycle was repeated until the change in weight was $\leq 0.01 \mathrm{~g}$ and the mass loss is the measure of abrasive wear to the specimen.

\subsection{Statistical analysis}

Statistically significant differences were determined using a one-way ANOVA and Tukey post hoc analysis. All data reported as mean \pm standard deviation.

\section{Results}

\subsection{Pore morphometry characterization}

The average architecture depth and percent porosity of the compression samples is shown in Table 1. No difference in pore sizes or strut spacing were measured from those reported previously (pore size: SP-250 $=284 \pm 35 \mu \mathrm{m}, \mathrm{SP}-350=341 \pm 49 \mu \mathrm{m}, \mathrm{SP}-450=416 \pm 54 \mu \mathrm{m}$ ) 
[2]. The average percent porosity, strut spacing, and architecture depth for the abrasion samples is shown in Table 2.

\subsection{Compression Testing}

Average yield stresses and moduli values are summarized for all samples in Table 3. No significant differences were found between pore sizes but the thinner pore architecture demonstrated a higher modulus and yield strength $(\mathrm{p}<0.001$ and $\mathrm{p}<0.001$, respectively). Representative stress-strain responses of surface porous PEEK are shown in Figure 1. As demonstrated, the surface porous curve can be decoupled into the solid and porous components. The pore architecture shows the typical three stage response of porous materials: linear elasticity, plastic deformation, and densification (Figure 2). The transition from plastic deformation to densification is marked by a transition in slope on the stress-strain curve from linear to a rapid increase approaching fully dense PEEK's modulus. After densification, the fully dense material behaves as the solid and closely parallels the solid stress-strain response.

Figure 3a compares the experimentally measured modulus of the samples to the theoretical modulus predicted by Equation 1

$$
E^{*}=E_{s}\left(1-V_{f}\right)^{2}
$$

where $E^{*}$ and $E_{s}$ are the elastic moduli of the porous materials and the material without porosity, respectively, and $V_{f}$ is the pore volume fraction [25]. The experimental moduli were slightly lower than the theoretical values, regardless of pore size or pore architecture depth.

Figure 3b compares the experimental compressive yield strength to the theoretical yield strength predicted by Gibson and Ashby's model for strength of open-cell foams in Equation 2 


$$
\sigma_{y}^{*}=0.23 \sigma_{y}\left(1-V_{f}\right)^{3 / 2}\left[1+\left(1-V_{f}\right)^{1 / 2}\right]
$$

where $\sigma_{y}^{*}$ is the yield strength of the foam and $\sigma_{y}$ is the yield strength of the solid material [26].

Equation 2 is only applicable for $70 \% \leq V_{f} \leq 96 \%$. In general, the experimental yield strength of samples with the thinner pore architecture were greater than the theoretical value, regardless of pore size, and the samples with the thicker pore architecture were below the theoretical value.

\section{3. $\mu$ CT Compression}

The in situ $\mu \mathrm{CT}$ compression testing revealed that the average percent porosity decreased as a function of strain (Figure $\mathbf{4 a}, \mathbf{b}$ ) and was inversely related to the applied stress. Figure $\mathbf{4 c}$ also shows that the average strut spacing decreased as a function of strain for the thick samples. Valid measurements for the strut spacing were not achievable for the thin samples due to the fact that the feature sizes are on the same size scale of the region of interest, especially at higher strains, limiting the measurements to the volume of interest in contrast to feature size. Similarly, the relatively high standard deviations of percent porosity of thin samples are likely due to the small volume of interest leading to greater sensitivity to variations. The data also demonstrate good agreement with the prior compression results (dotted line on Figure 4a, b).

Figure 5 shows $\mu \mathrm{CT}$ reconstructions of representative thin and thick samples at various strains. Pore morphometrics were also evaluated as a function of various regions of a representative thick pore architecture. The sample was divided into three regions: the bottom $1 / 3$ of the sample near the solid-pore interface, the middle $1 / 3$ of pore architecture, and the top $1 / 3$ of pore architecture at air-pore interface. The results (Figure 6) demonstrate uniform deformation throughout the porous region sample.

\subsection{Taber Abrasion Test}


Average mass loss values after 100 cycles are summarized in Table 4. No significant differences were found between any of the samples. Representative images before and after 100 cycles of abrasion are shown in Figure 7. $\mu \mathrm{CT}$ comparing the pore structure before and after abrasion revealed a slight densification of the pore network and flattening of the top pore architecture (Figure 8). Quantitative analysis of the $\mu \mathrm{CT}$ data demonstrated a small reduction in pore architecture depth for SP-250 abraded compared to non-abraded samples $(0.645 \pm 0.051 \mu \mathrm{m}$ vs $0.684 \pm 0.053 \mu \mathrm{m}$, respectively, $\mathrm{p}<0.05)$. No difference in architecture depth was found between abraded and non-abraded samples in the 350 or 450 groups. A small change in strut spacing was also observed for SP-250 abraded compared to non-abraded samples (149 $\pm 2.3 \mu \mathrm{m}$ vs $156 \pm 0.55 \mu \mathrm{m}$, respectively, $\mathrm{p}<0.05)$ and for 350 abraded compared to non-abraded $(226 \pm 3.6 \mu \mathrm{m}$ vs $232 \pm 2.7 \mu \mathrm{m}$, respectively, $\mathrm{p}<0.05)$. No change in strut spacing between 450 groups was observed and no change in porosity was observed between any groups.

\section{Discussion}

While previous studies characterized the tensile and fatigue properties of PEEK containing surface porosity [1-3] and the strength-property relationships in solid PEEK are well known [27], local mechanical behavior of the pore architecture has not been previously characterized or understood. In this study we evaluated the compressive and wear properties of PEEK with surface porosity to provide understanding of how the porous architecture affects the mechanical properties the structure-property relationship and to inform future design of surface porous materials.

Compression testing and microCT analysis demonstrated three stages of deformation in the surface porous architecture - linear elastic, plastic, and densification - regardless of pore size or architecture depth. This deformation behavior is characteristic of foams and has been 
described previously $[22,23]$. It is therefore helpful to consider surface porous PEEK as a composite material consisting of a solid PEEK core directly integrated with an outer PEEK foam. Foams generally have reduced mechanical stiffness and strength but enhanced compressibility [22] and can accommodate large strains.

In the initial regime of deformation, the cell wall 'struts' undergo elastic deformation and uniaxially bend corresponding to a small drop in pore size. The elastic regime of the porous architecture occurs below $\sim 5 \%$ strain. With increasing deformation up to $\sim 50 \%$ strain, the struts buckle and the material experiences plastic deformation (Figure 9). The free volume inherent due to the porosity leads to pore collapse and results in a rapid drop in the average pore size over the strain corresponding to the plastic regime (Figure 4). The increase in axial strain took place with minimal transverse strain effects at low strains, highlighting the unique relationship between axial and transverse strains (Poisson effect) for foams [22]. The transverse strain becomes significant once the foam reaches the densification stage. Once all struts have buckled, densification occurs (>50\% strain) and the change in cell size slows. Upon densification the material approaches the stress-strain response of the solid material (Figure 1).

All samples demonstrated similar stress-strain responses and there were no observed differences in deformation behavior over the range of pore sizes considered here. This is in agreement with previous studies on porous polymers that showed that the percent porosity had a greater influence on properties than pore size within certain size ranges [28]. While pore size showed little effect, the compressive response of the porous architecture was different for the two architecture depths. The variation in strength and stiffness with architecture depth is likely due to the increased porosity of the thicker pore architectures. This can be explained by the following: to create thicker porous architectures, the PEEK had to be pressed greater distances 
through the salt network. These greater distances required a higher force resulting in greater packing of the salt and subsequently a higher percent porosity. This relationship between architecture depth and percent porosity of the compression samples is highlighted in Figure 10.

The compression tests demonstrated that surface porous PEEK is much more ductile but yields at lower stresses than when tested in tension $[1,2]$. This difference is due to the poroussolid architecture geometry and relative loading directions; the tensile samples are set up in a way to share tensile stresses between porous and smooth regions while the compression samples are set up such that the porous and solid regions bear the same stresses. The pores allow for large strains in compression while under tension, cracks can nucleate from the pore, decreasing the ductility. When comparing strengths, compressive forces yield the pores at relatively low loads. In contrast, surface porous PEEK has a high yield strength as the solid core is able to carry the majority of the load [1-3]. These results are clearly dependent on the fact that in compression the pore architecture and solid region were tested in series; tension tests evaluated the pore architecture and solid region in parallel. It is hypothesized that compressive testing of the pore architecture and solid region in parallel would result in a much higher yield strength with lower corresponding strains. Furthermore, tensile testing of the pore architecture and solid region in series would result in much lower yield strengths and would either give the tensile strength of the pore architecture or the tensile strength at the interface (tensile adhesion test, ASTM F1147-05). These results are important to consider when evaluating surface porous PEEK as a potential material in load bearing orthopedic applications.

Although the differential porosities explain most of the observed compression results, it is important to note that the yield strength of thin pore architectures lie, in general, above the theoretically predicted yield strength and the yield strength of the thick architectures lie below. 
These observed differences could be due to the effects of the substrate. Structural support of the underlying substrate might lead to greater measured strengths in the thinner pore architectures; in the thicker pore architectures, this effect would most likely be negligible. Substrate effects, commonly studied in thin films [29-34], can be due to different microstructures near the interface or due to the constraint of the substrate on the films deformation mechanism. To evaluate whether there existed different microstructure in the various architectures, the percent porosity as a function of the normalized pore architecture depth for the thinnest and thickest pore architectures studied in the monotonic compression were plotted in Figure 11. As shown, the thin architecture not only has a lower porosity throughout the pore architecture, but the transition to the solid (the interface thickness) is a much greater percent of the overall pore architecture depth. Therefore, the less porous microstructure near the interface, in combination with the lower overall porosity, likely contributes to an increase in the observed yield strength.

The in situ $\mu \mathrm{CT}$ compression scans provided further insight into deformation of the pore architecture. The data demonstrated very good agreement between the pore morphometrics of all three samples indicating that the pore architecture created is consistent with high reproducibility. The results also showed uniform deformation throughout the sample (Figure 6). Importantly, the $\mu \mathrm{CT}$ compression data reveals that the sample can deform up to $40 \%$ of its original size and still offer high porosity for ingrowth (over $50 \%$ porous, or $\sim 70 \%$ of the original open space). The stress at 50\% strain is around $14 \mathrm{MPa}$. This indicates that in an application such as lumbar spinal fusion, where the average cage is between 90 and $330 \mathrm{~mm}^{2}$, a surface porous PEEK implant could withstand a minimum of $1260 \mathrm{~N}$ and as much as $4620 \mathrm{~N}$ of load while still offering high porosity for ingrowth. These loads are above those commonly placed on the spine during daily activities [35]. 
Abrasion on surface porous PEEK and injection molded PEEK yielded unexpected results. While porous samples are expected to wear at a higher rate than their smooth counterparts, no differences in the mass loss was observed between surface porous PEEK samples and injection molded PEEK. Although the coefficient of friction on surface porous samples is undoubtedly higher than injection molded, visual inspection and $\mu \mathrm{CT}$ revealed a difference in wear mechanism. The normal mechanism of wear in this test setup is particle shedding. However, an additional wear mechanism for the surface porous groups - pore architecture collapse and slight densification of the pores - appears to be also be present also occurs in surface porous groups. $\mu \mathrm{CT}$ analysis revealed that the abrasion reduced the pore architecture depth in SP-250 samples and reduced the strut size in SP-250 and 350 samples, indicating that the abrasion results in a flattening of the surface porous architecture along the wear path in addition to densification of the pores (Figure 8).

In addition to another wear mechanism being active, there is a change in the particle shedding mechanism. The ceramic wheel surface comes in contact with single asperities on the pore surface and the real area of contact on porous surfaces is usually much smaller than the nominal contact area [36]. The wear rate is proportional to the number of such asperities and therefore the wear rate on the surface porous samples, despite an increase in roughness, is not higher than the injection molded surface in which the wheel surface would contact much more material surface at a given time. Therefore, while friction is dominated by the contact events that occur without damage, wear is dominated by the probability that a particular contact event results in rupture, explaining why there was no increase in mass loss on surface porous samples.

This study provides insight into the deformation mechanics of the porous architecture on surface porous PEEK and demonstrates that the material is suitable for load bearing applications 
such as spinal fusion. Surface porous PEEK exhibited the ability to withstand physiologically relevant loads while still maintaining a high degree of porosity available for potential boneingrowth. Furthermore, no increase in wear was observed on surface porous samples. While future work is needed to explore the time-dependent deformation (creep) at longer time points and cyclic compression resistance, the results thus far are promising for future applications of the material in orthopedics.

\section{Conclusions}

This study probed the mechanics of the pore architecture of surface porous PEEK and the following observations have been made:

(1) The compressive response of surface porous PEEK is characterized by three stages linear elasticity (bending), plastic deformation (buckling), and densification - as predicted by numerical models of foam deformation.

(2) Pore size $(212-500 \mu \mathrm{m})$ has no effect on any of the measured mechanical properties.

(3) The overall percent porosity correlates to changes in architecture depth due to the higher pressure used during processing of thicker pore architectures.

(4) Variations in porosity drive the observed differences in strength and stiffness.

(5) There was no observed increase in mass loss during abrasion on surface porous samples; abraded surface porous samples showed slight densification of the pore network

(6) Surface porous PEEK can withstand physiologically relevant loads while still maintaining a high degree of porosity available for bone-ingrowth. 


\section{Acknowledgements}

This work was supported by Solvay Advanced Polymers. The authors would like to thank Joanna

Gochuico, Haley Harris, and Kevin Chriackal for their assistance in running the abrasion

experiments and processing samples. N.T.E is supported by the National Science Foundation

Graduate Research Fellowship under Grant No. 2013162284. The technology disclosed in this manuscript is being commercialized by Vertera, Inc.

\section{References}

1. Evans, N.T., et al., High-strength, surface-porous polyether-ether-ketone for loadbearing orthopedic implants. Acta Biomater, 2015. 13: p. 159-67.

2. Torstrick, F.B., et al., Do Surface Porosity and Pore Size Influence Mechanical Properties and Cellular Response to PEEK? Clinical Orthopaedics and Related Research®, 2016: p. 1-11.

3. Evans, N.T., et al., Impact of surface porosity and topography on the mechanical behavior of high strength biomedical polymers. Journal of the Mechanical Behavior of Biomedical Materials, 2016. 59: p. 459-473.

4. Nachemson, A., Lumbar intradiscal pressure: experimental studies on post-mortem material. Acta Orthopaedica, 1960. 31(S43): p. 1-104.

5. McGill, S.M., Loads on the lumbar spine and associated tissues. 1990: CRC Press, Boca Raton.

6. Schultz, A.B. and G.B. Andersson, Analysis of loads on the lumbar spine. Spine, 1981. 6(1): p. 76-82.

7. Kuster, M.S., et al., Joint load considerations in total knee replacement. Journal of Bone \& Joint Surgery, British Volume, 1997. 79(1): p. 109-113.

8. Stadelmann, V.A., A. Terrier, and D.P. Pioletti, Microstimulation at the bone-implant interface upregulates osteoclast activation pathways. Bone, 2008. 42(2): p. 358-64.

9. Scholes, S.C., et al., The Location and Friction of Conventional UHMWPE, Novel Compliant Layer, and Hard Bearing Surfaces for use in Total Hip Prosteses, in Friction, Lubrication and Wear of Artificial Joints, I.M. Hutchings, Editor. 2003, John Wiley \& Sons.

10. ASTM F1978-12, Standard Test Method for Measuring Abrasion Resistance of Metallic Thermal Spray Coatings by Using the Taber Abrase. 2012, ASTM International: West Conshohocken, PA. 
11. Kurtz, S.M. and J. Nevelos, Arthroplasty Bearing Surfaces, in PEEK biomaterials handbook. 2011, William Andrew.

12. Wang, A., et al., Suitability and limitations of carbon fiber reinforced PEEK composites as bearing surfaces for total joint replacements. Wear, 1999. 225-229, Part 2: p. 724727.

13. Scholes, S. and A. Unsworth, The wear properties of CFR-PEEK-OPTIMA articulating against ceramic assessed on a multidirectional pin-on-plate machine. Proceedings of the Institution of Mechanical Engineers, Part H: Journal of Engineering in Medicine, 2007. 221(3): p. 281-289.

14. Jones, E., A. Wang, and R. Streicher. Validating the limits for a PEEK composite as an acetabular wear surface. in 27 th Annual Meeting of the Society for Biomaterials in Conjunction with the 33 rd International Biomaterials Symposium. 2001. Saint Paul, MN.

15. Howling, G., et al., Biological response to wear debris generated in carbon based composites as potential bearing surfaces for artificial hip joints. Journal of Biomedical Materials Research Part B: Applied Biomaterials, 2003. 67(2): p. 758-764.

16. Utzschneider, S., et al., Inflammatory response against different carbon fiber-reinforced PEEK wear particles compared with UHMWPE in vivo. Acta Biomaterialia, 2010. 6(11): p. 4296-4304.

17. Rivard, C.H., S. Rhalmi, and C. Coillard, In vivo biocompatibility testing of peek polymer for a spinal implant system: a study in rabbits. J Biomed Mater Res, 2002. 62(4): p. 48898.

18. Chen, Q., D.Y. Li, and B. Cook, Is porosity always detrimental to the wear resistance of materials? - A computational study on the effect of porosity on erosive wear of $\mathrm{TiC} / \mathrm{Cu}$ composites. Wear, 2009. 267(5-8): p. 1153-1159.

19. Vardavoulias, M., C. Jouanny-Tresy, and M. Jeandin, Sliding-wear behaviour of ceramic particle-reinforced high-speed steel obtained by powder metallurgy. Wear, 1993. 165(2): p. 141-149.

20. Malyshev, V., A. Volkhin, and B. Gantimirov, Tribological Characteristics Improvement of Wear Resistant MAO-Coatings. Journal of Coatings, 2013. 2013: p. 5.

21. ZHANG, L., et al., Effect of porosity on wear resistance of $\mathrm{SiC} p / C u$ composites prepared by pressureless infiltration. Transactions of Nonferrous Metals Society of China, 2008. 18(5): p. 1076-1082.

22. Di Prima, M.A., Thermo-mechanical and Micro-structural Characterization of Shape Memory Polymer Foams, in Materials Science and Engineering. 2009, Georgia Institute of Technology. p. 165.

23. Schraad, M.W. and F.H. Harlow, A stochastic constitutive model for disordered cellular materials: Finite-strain uni-axial compression. International Journal of Solids and Structures, 2006. 43(11-12): p. 3542-3568.

24. Hildebrand, T., et al., Direct three-dimensional morphometric analysis of human cancellous bone: microstructural data from spine, femur, iliac crest, and calcaneus. $\mathrm{J}$ Bone Miner Res, 1999. 14(7): p. 1167-74.

25. Ji, S., Q. Gu, and B. Xia, Porosity dependence of mechanical properties of solid materials. Journal of Materials Science, 2006. 41(6): p. 1757-1768.

26. Gibson, L.J. and M.F. Ashby, Cellular Solids: Structure and Properties. 1999, Cambridge, United Kingdom: Cambridge University Press. 
27. Jones, D.P., D.C. Leach, and D.R. Moore, Speciality Polymers 84Mechanical properties of poly(ether-ether-ketone) for engineering applications. Polymer, 1985. 26(9): p. 13851393.

28. DiRienzo, A.L., et al., Porous poly(para-phenylene) scaffolds for load-bearing orthopedic applications. Journal of the Mechanical Behavior of Biomedical Materials, 2014. 30(0): p. 347-357.

29. Hainsworth, S., T. Bartlett, and T. Page, The nanoindentation response of systems with thin hard carbon coatings. Thin Solid Films, 1993. 236(1): p. 214-218.

30. Burnett, P. and D. Rickerby, Assessment of coating hardness. Surface engineering, 1987. 3(1): p. 69-76.

31. Chechenin, N., J. Bøttiger, and J. Krog, Nanoindentation of amorphous aluminum oxide films I. The influence of the substrate on the plastic properties. Thin Solid Films, 1995. 261(1): p. 219-227.

32. Saha, R. and W.D. Nix, Effects of the substrate on the determination of thin film mechanical properties by nanoindentation. Acta Materialia, 2002. 50(1): p. 23-38.

33. Gamonpilas, C. and E.P. Busso, On the effect of substrate properties on the indentation behaviour of coated systems. Materials Science and Engineering: A, 2004. 380(1): p. 5261.

34. Bilbrey, J. Removing substrate effects from nanoindentation measurements. June 112015 [cited 2016; Available from: http://www.materials360online.com/newsDetails/54037.

35. Rohlmann, A., et al., Activities of Everyday Life with High Spinal Loads. PLoS ONE, 2014. 9(5): p. e98510.

36. Hirani, H., Chapter 8: Mixed Lubrication, in Fundamentals of Engineering Tribology with Applications. 2016, Cambridge University Press: Dehli, India. 
Table 1. Pore morphology of surface porous PEEK samples used in compression testing. Values represent the average \pm one standard deviation.

\begin{tabular}{ccccc}
\hline & \multicolumn{2}{c}{ Thin Pore Depth } & \multicolumn{2}{c}{ Thick Pore Depth } \\
\cline { 2 - 5 } & $\begin{array}{c}\text { Pore Architecture } \\
\text { Depth }(\mathrm{mm})\end{array}$ & \% Porosity & $\begin{array}{c}\text { Pore Architecture } \\
\text { Depth }(\mathrm{mm})\end{array}$ & \% Porosity \\
\hline SP-250 & $0.918 \pm 0.22$ & $68.1 \pm 2.3$ & $2.25 \pm 0.093$ & $72.7 \pm 1.9$ \\
SP-350 & $1.10 \pm 0.23$ & $71.3 \pm 0.89$ & $2.00 \pm 0.56$ & $75.4 \pm 2.9$ \\
SP-450 & $1.09 \pm 0.071$ & $70.8 \pm 1.5$ & $2.19 \pm 0.21$ & $72.1 \pm 1.8$ \\
\hline
\end{tabular}

Table 2. Pore morphology of surface porous PEEK samples used in abrasion testing. Values represent the average \pm one standard deviation.

\begin{tabular}{cccc}
\hline & \% porosity & strut spacing $(\boldsymbol{\mu m})$ & $\begin{array}{c}\text { pore architecture } \\
\text { depth }(\boldsymbol{\mu m})\end{array}$ \\
\hline SP-250 & $65.6 \pm 1.0$ & $156 \pm 0.55$ & $684 \pm 53$ \\
SP-350 & $63.9 \pm 1.8$ & $232 \pm 3.0$ & $848 \pm 79$ \\
SP-450 & $62.3 \pm 3.3$ & $244 \pm 2.8$ & $836 \pm 97$ \\
\hline
\end{tabular}

Table 3. Modulus and yield strength of the surface porous PEEK samples tested in this study. Values represent the average \pm one standard deviation.

\begin{tabular}{ccccc}
\hline & \multicolumn{2}{c}{ Thin Pore Depth } & \multicolumn{2}{c}{ Thick Pore Depth } \\
\cline { 2 - 5 } & Modulus (MPa) & $\begin{array}{c}\text { Offset Yield } \\
(\mathrm{MPa})\end{array}$ & Modulus (MPa) & $\begin{array}{c}\text { Offset Yield } \\
(\mathrm{MPa})\end{array}$ \\
\hline SP-250 & $110 \pm 12$ & $10.8 \pm 1.22$ & $60.8 \pm 7.6$ & $4.48 \pm 0.76$ \\
SP-350 & $109 \pm 18$ & $8.72 \pm 1.68$ & $61.8 \pm 6.8$ & $4.33 \pm 0.63$ \\
SP-450 & $90.7 \pm 9.2$ & $10.6 \pm 0.76$ & $52.5 \pm 8.1$ & $4.51 \pm 0.67$ \\
\hline
\end{tabular}


Figure 1. Stress-strain response of a representative surface porous-350 sample relative to the response of just the solid and porous components only. Solid line is from measured data and dashed lines are from calculated values.

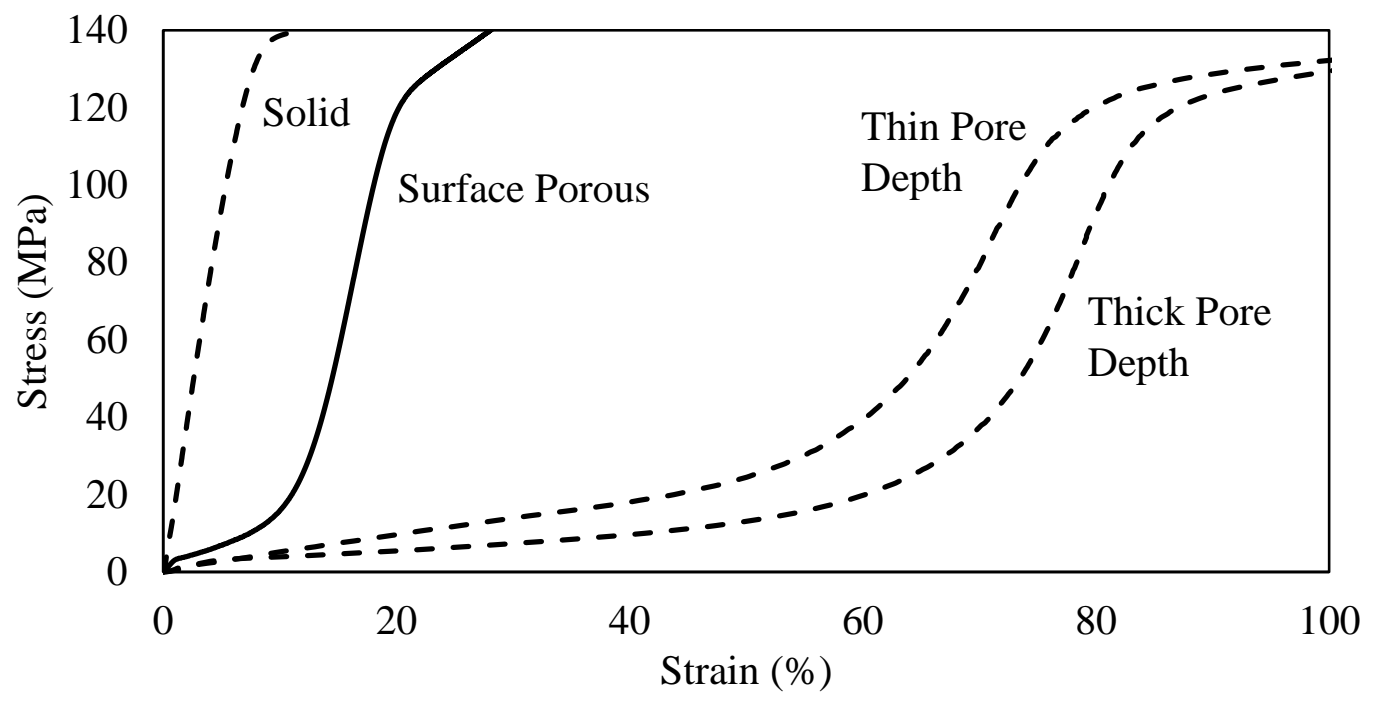


Figure 2. Stress-strain behavior of the porous architecture isolated from the stress-strain response of surface porous PEEK. The response demonstrates the typical three staged response of porous foam materials: linear elasticity (i.e. bending), plastic yielding (i.e. buckling), and densification.

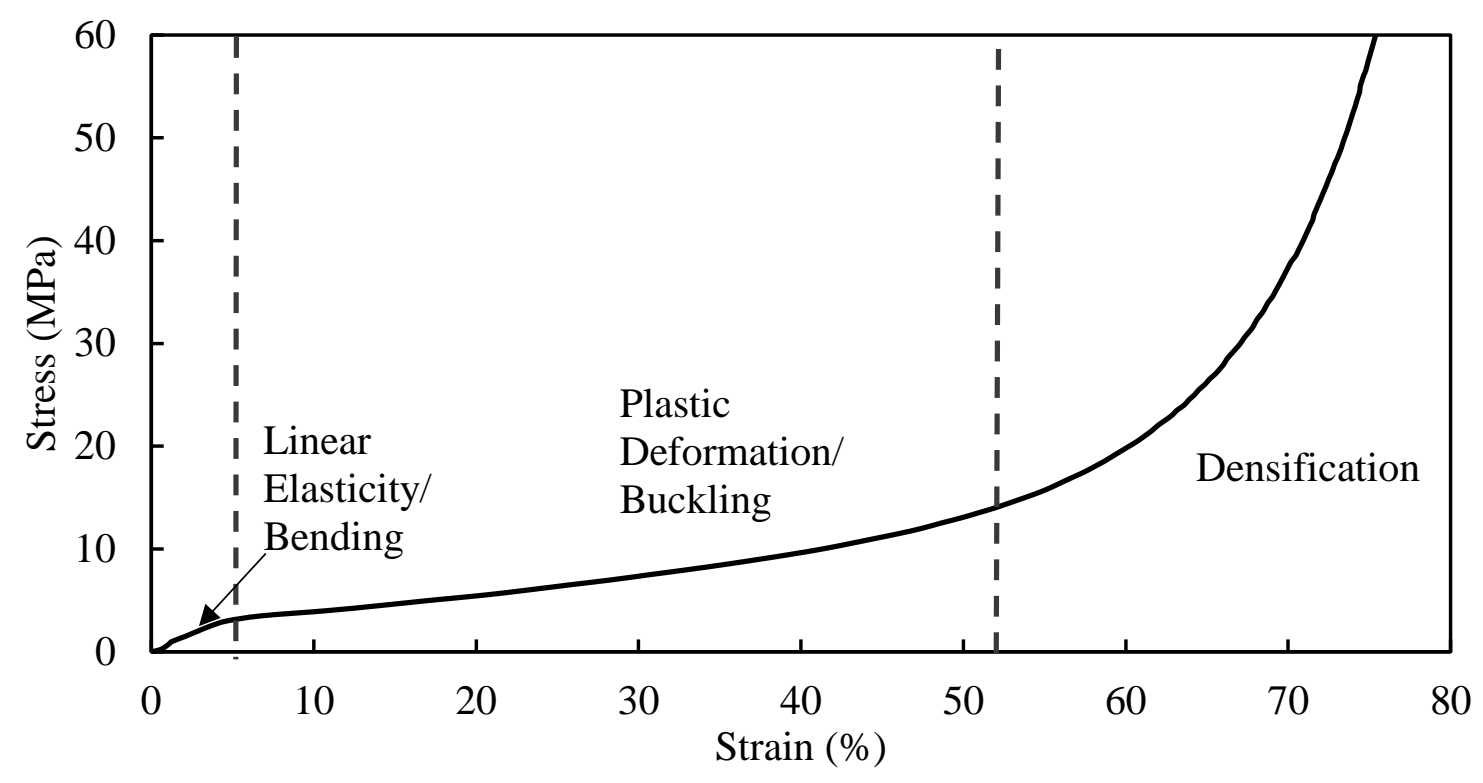


Figure 3. (A) Experimental modulus of surface porous PEEK samples compared to the theoretical modulus predicted by Equation 1. (B) Experimental yield strength of surface porous PEEK samples compared to the theoretical yield strength predicted by Equation 2.

(A)

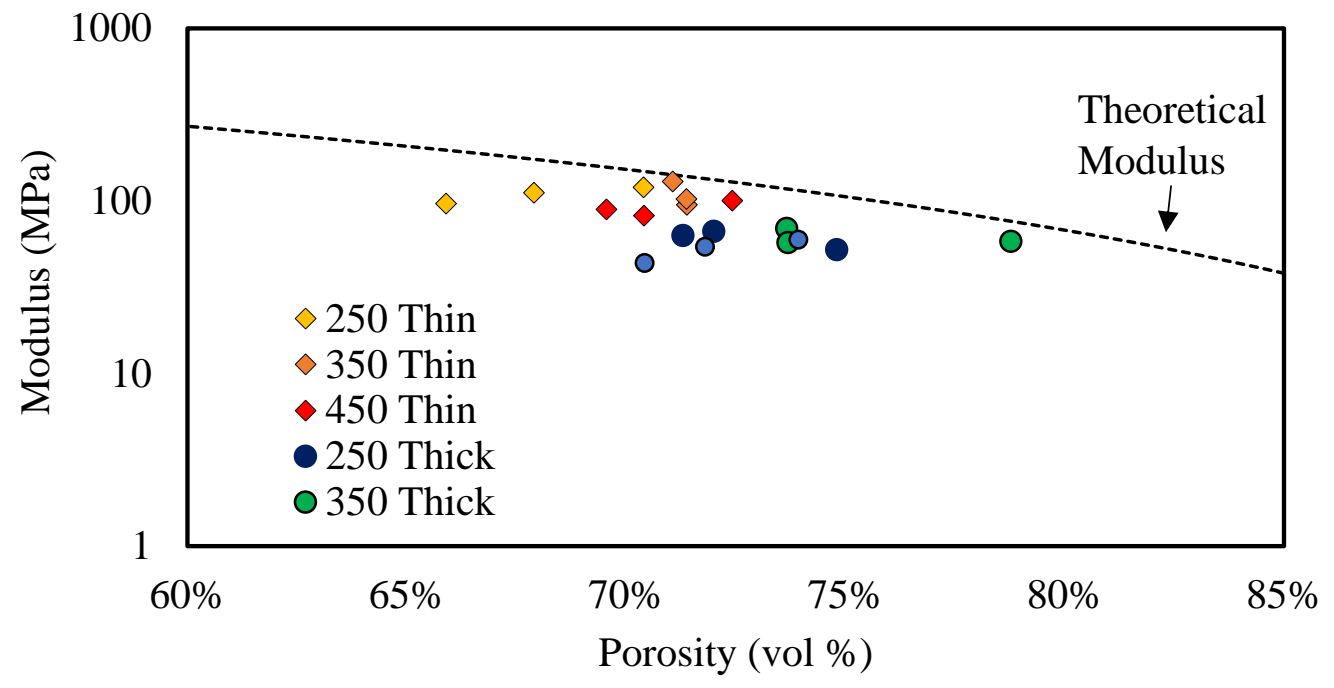

(B)

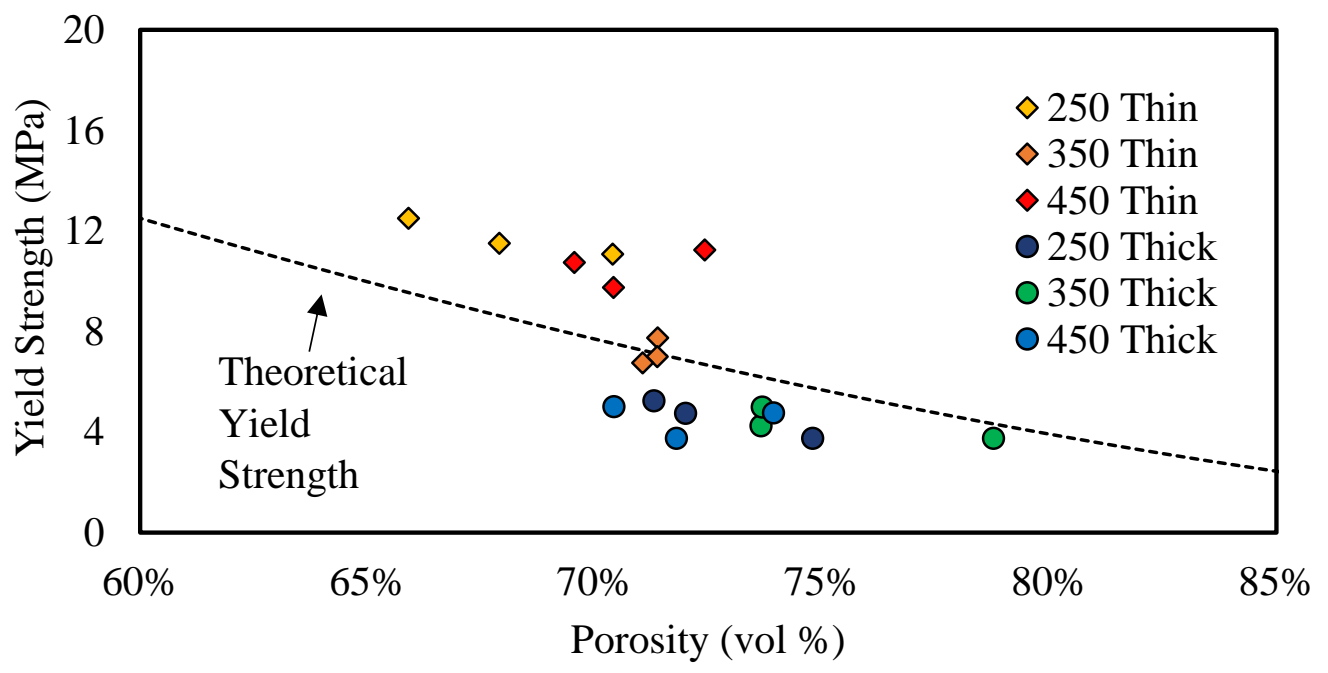


Figure 4. Microstructural response of surface porous PEEK to deformation. Plot of average percent porosity versus strain with the stress-strain plot included for comparison. The dashed line is a representative stress-strain curve from Figure $\mathbf{2}$ demonstrating good agreement between the two tests ((A) thick pore depth, (B) thin pore depth). (C) Plot of average strut spacing versus strain for thick pore depths. Error bars represent \pm one standard deviation.

(A)

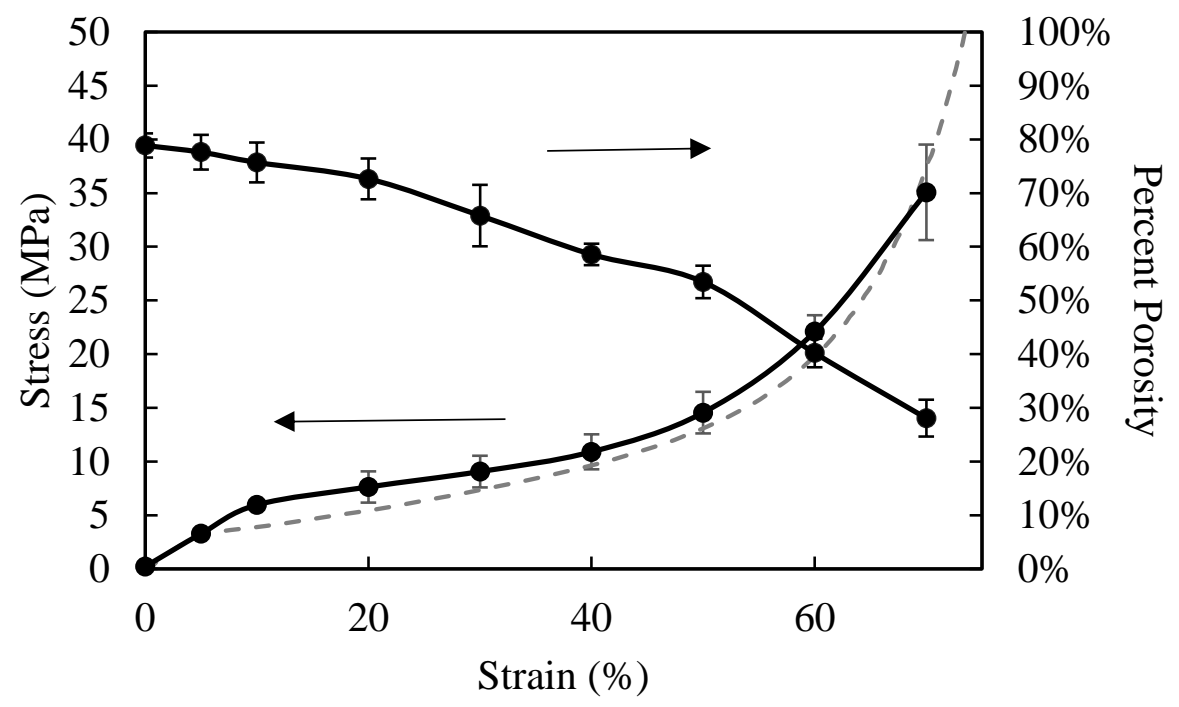

(B)

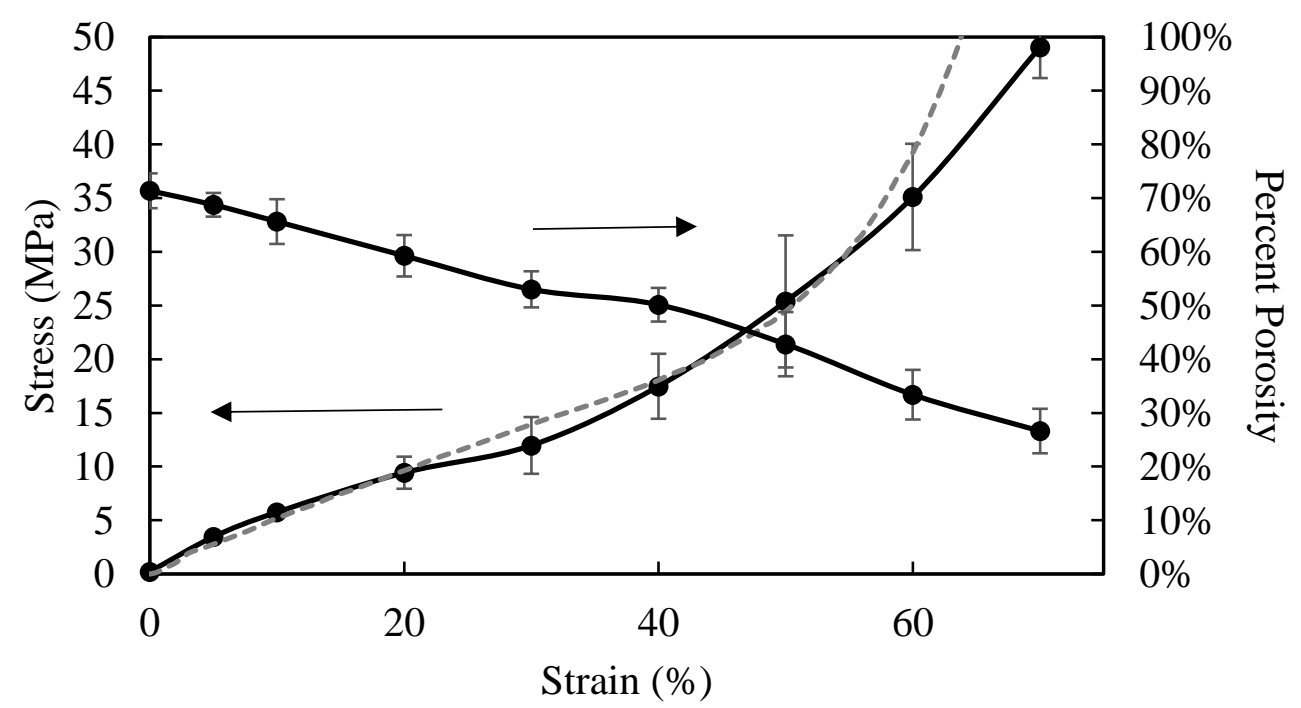


(C)

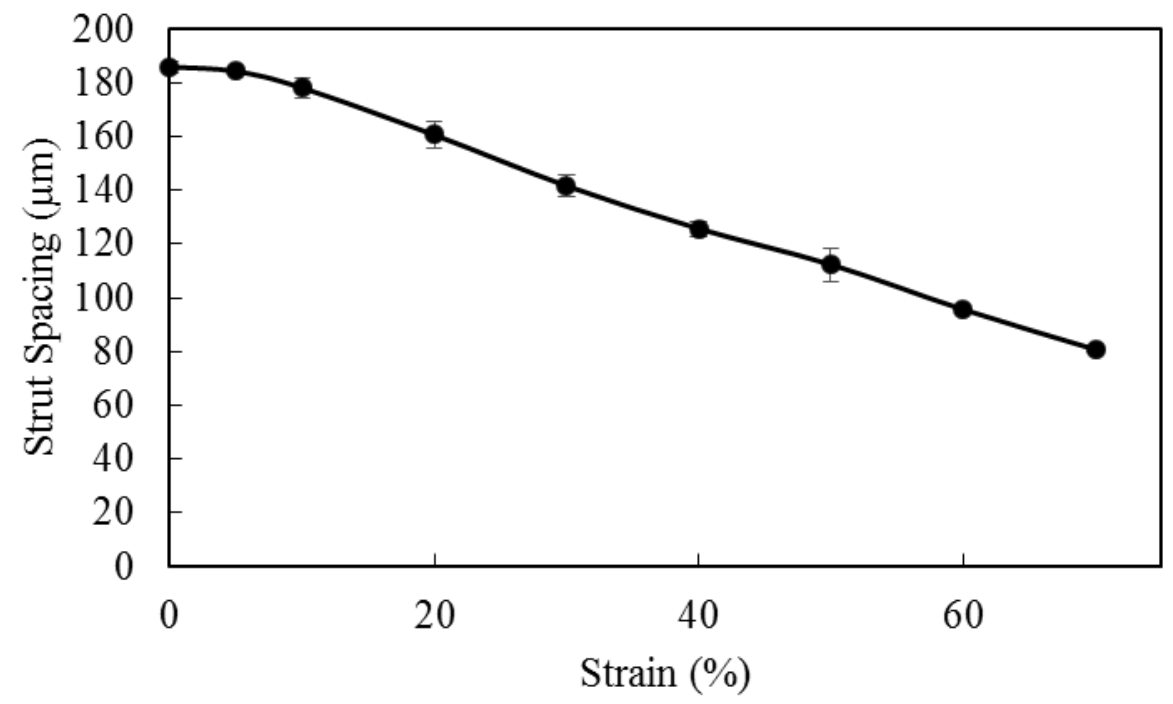


Figure 5. Representative $\mu \mathrm{CT}$ reconstructions of the porous architecture at various strains: (A) thick pore depth, (B) thin pore depth

(A)
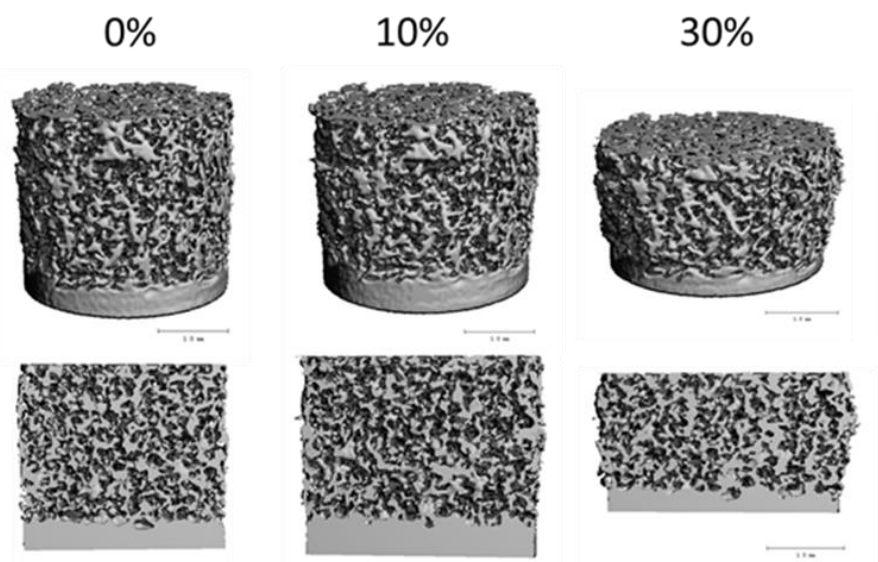

$50 \%$

$70 \%$
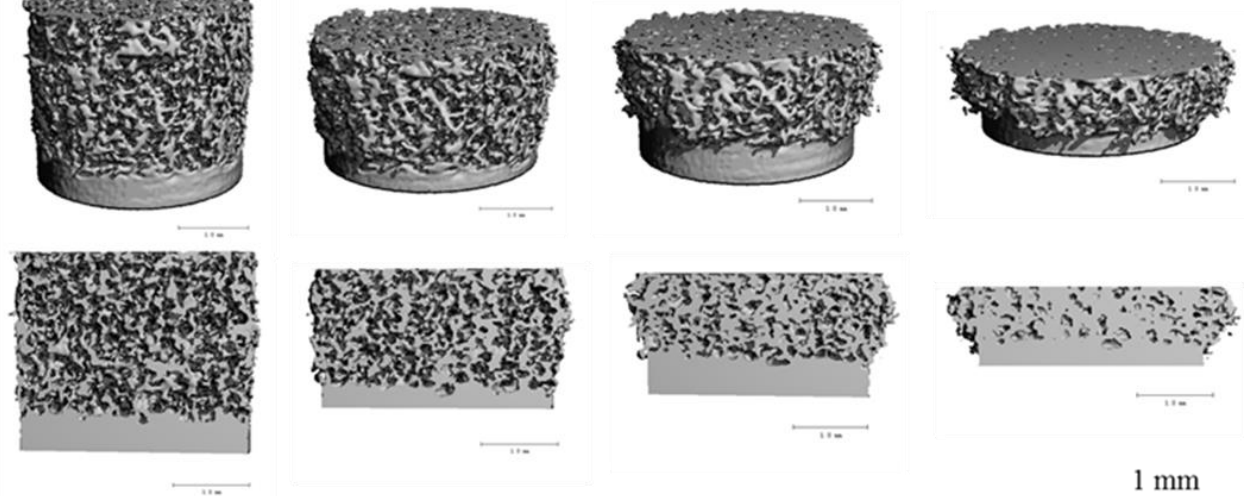

(B)
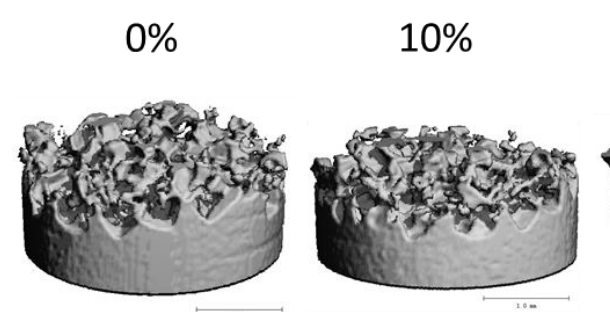

$30 \%$

$50 \%$

$70 \%$
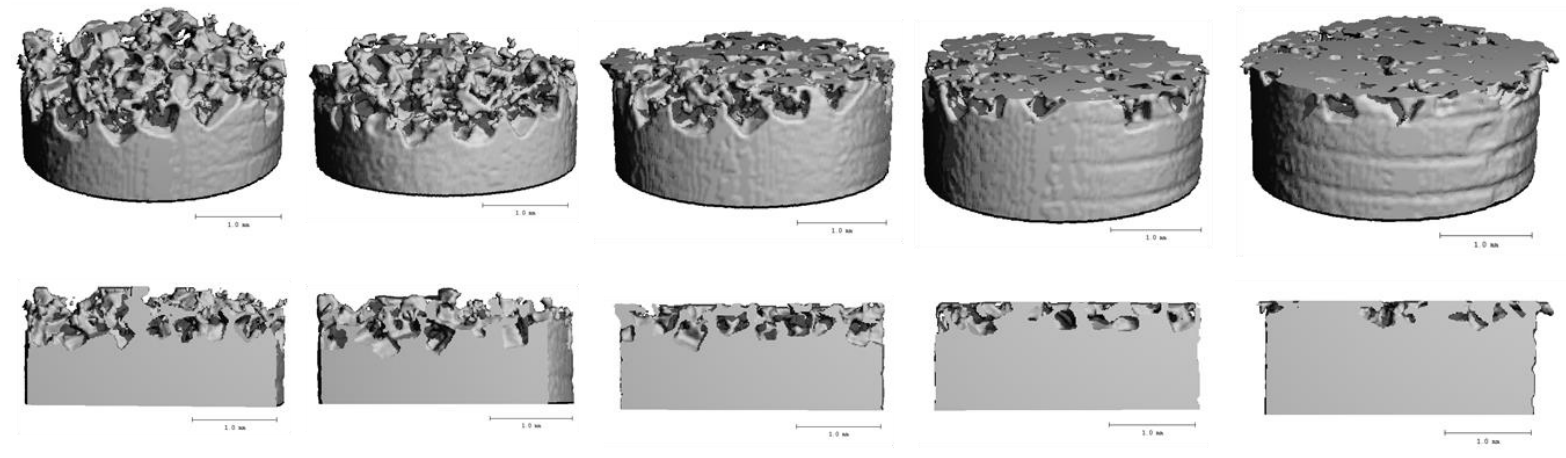

$1 \mathrm{~mm}$ 
Figure 6. Characterization of the microstructure as a function of deformation in three regions of a representative sample: bottom $1 / 3$ of porous region at the pore-solid interface, middle $1 / 3$ of porous region, and top $1 / 3$ of porous region at pore-air interface. (A) Percent porosity as a function of strain. (B) Strut spacing as a function of strain.

(A)

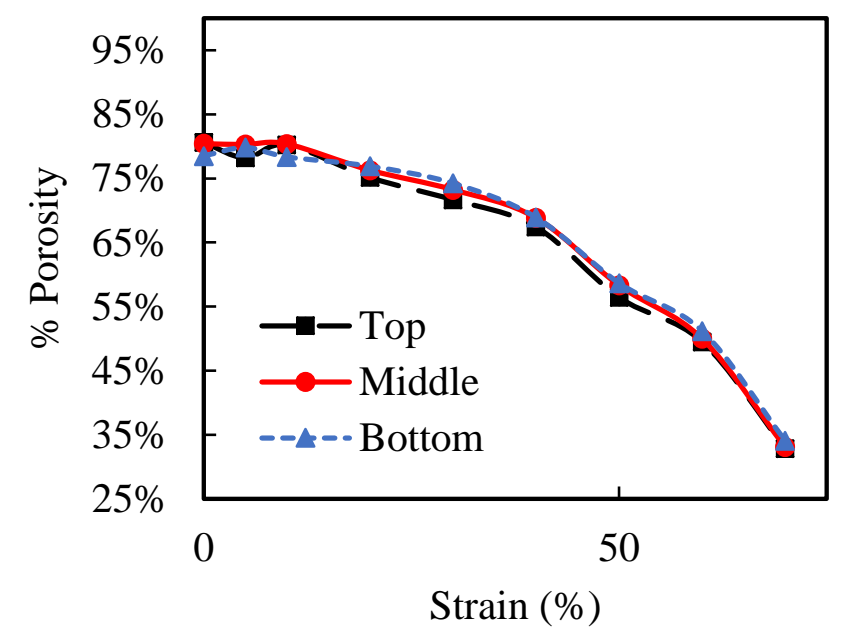

(B)

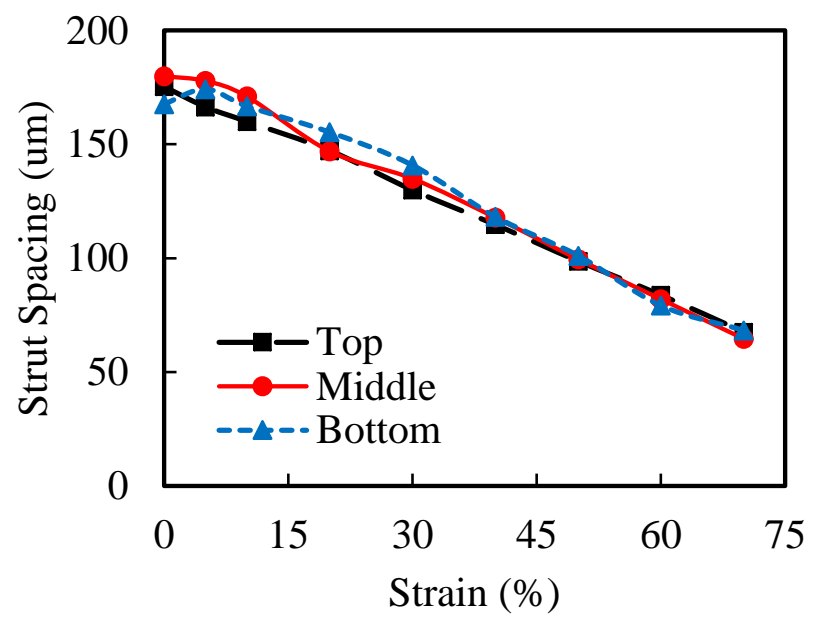


Table 4. Measured mass loss after 100 cycles. No significant differences were found between any of the samples.

\begin{tabular}{cc}
\hline Sample & $\begin{array}{c}\text { Mass Loss } \\
(\mathbf{m g})\end{array}$ \\
\hline SP 250 & $31.4 \pm 9.2$ \\
SP 350 & $27.6 \pm 12.3$ \\
SP 450 & $29.0 \pm 3.3$ \\
Injection Molded & $39.0 \pm 18$ \\
\hline
\end{tabular}

Figure 7. Images of the surface before (A) and after (B) abrasion. The top row are surface porous samples, the bottom row injection molded.

(A)
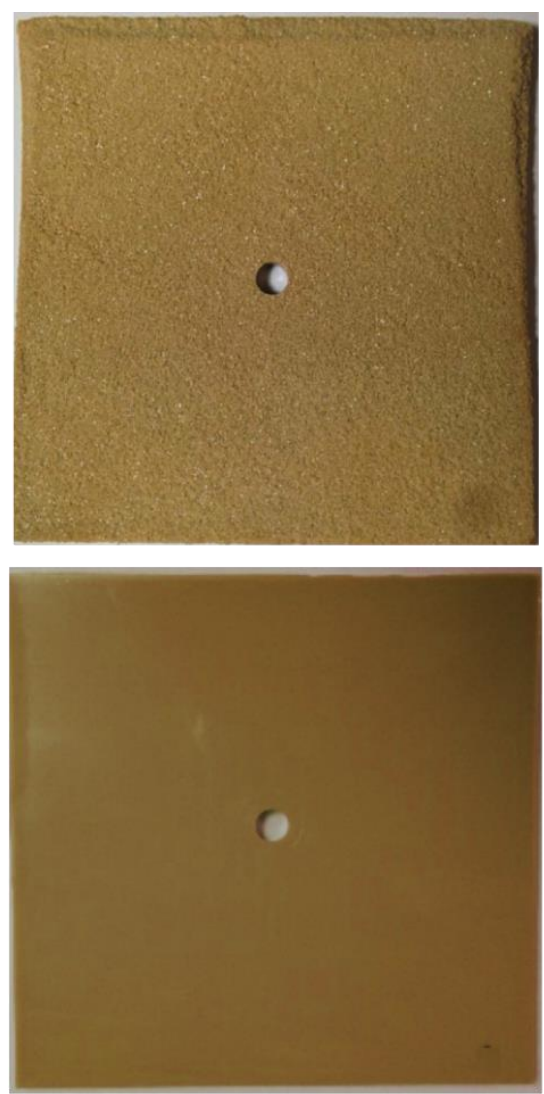

(B)
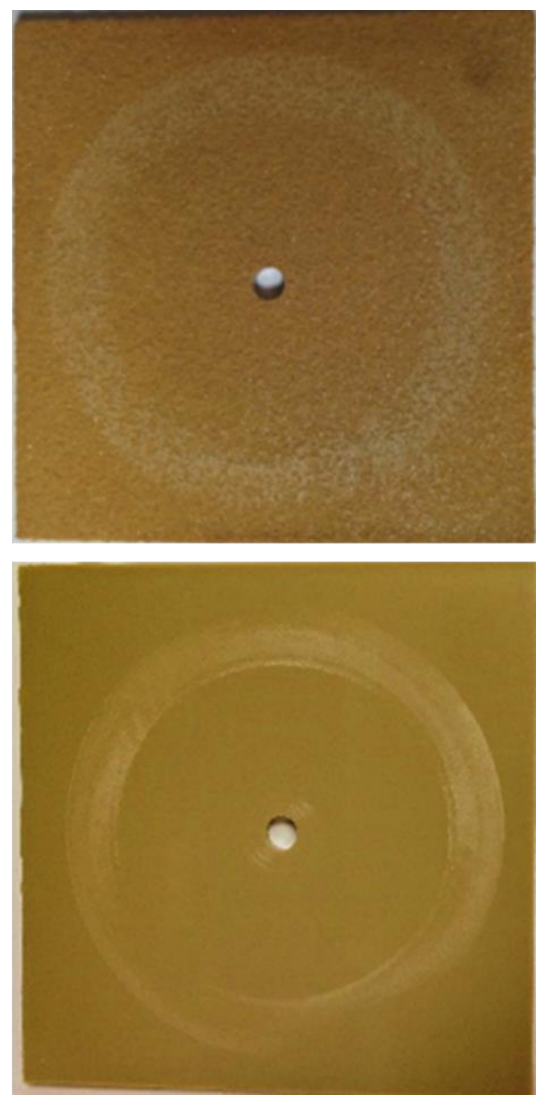
Figure 8. Representative $\mu \mathrm{CT}$ reconstructions of surfaces before and after abrasion. (A) Crosssection of PEEK-SP-250 pre-abrasion. (B) PEEK-SP-250 post-abrasion. (C) Surface (top-view) of PEEK-SP-250 pre-abrasion. (D) Surface of PEEK-SP-250 post-abrasion.

(A)

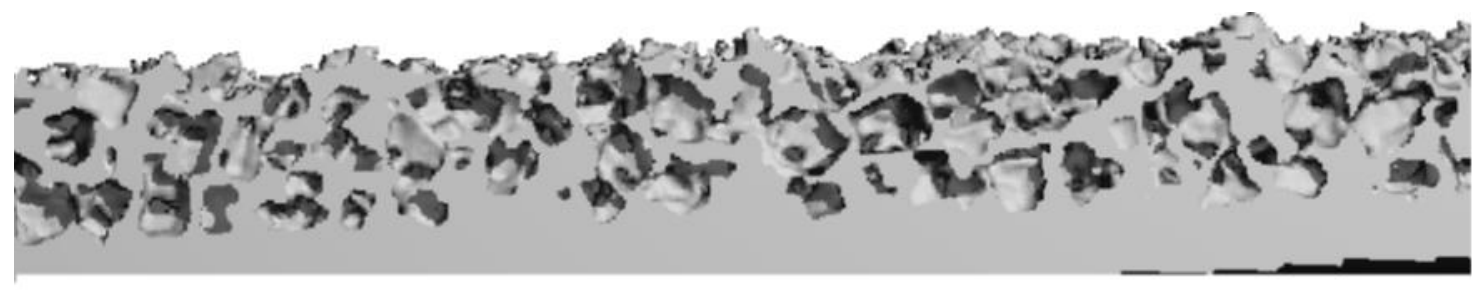

$1.0 \mathrm{man}$

(B)

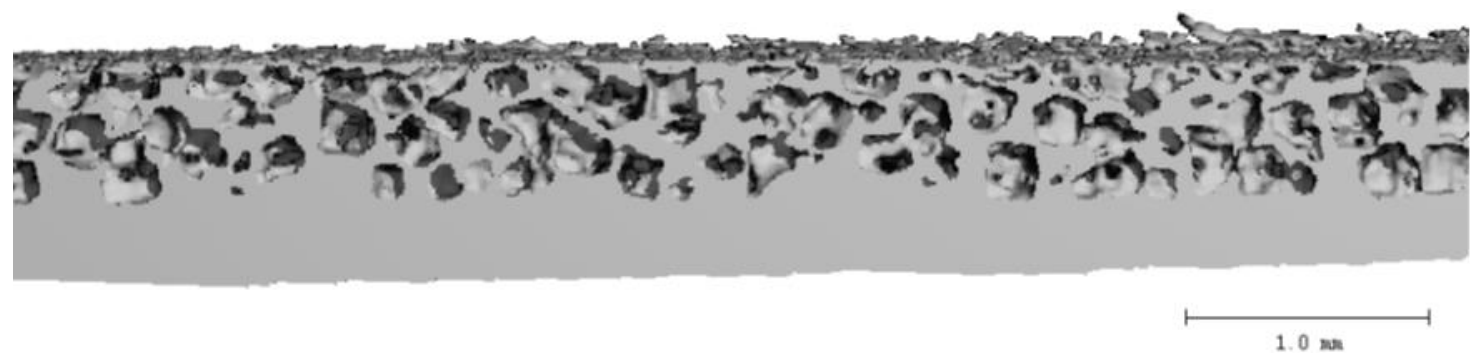

(C)

(D)
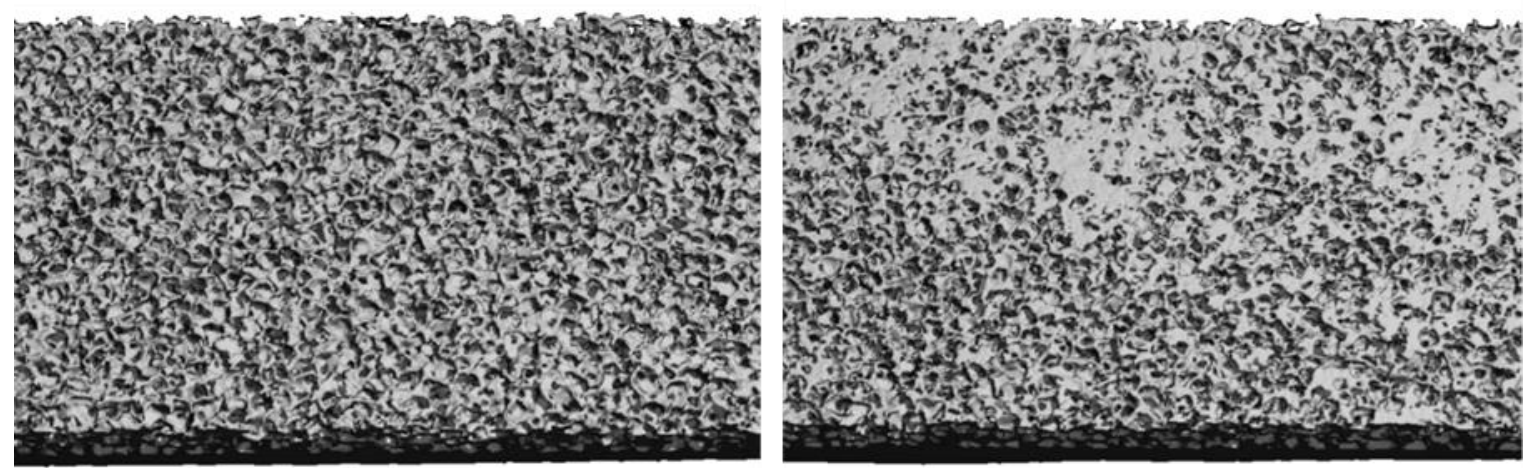

$1.0 \mathrm{~m}$

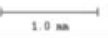


Figure 9. Representative $\mu \mathrm{CT}$ slices of the porous architecture (thick pore depth) at various strains. The top row is the entire sample (scale bar is $1 \mathrm{~mm}$ ) and the bottom row is zoomed in on the same porous region (scale bar is $100 \mu \mathrm{m}$ ).
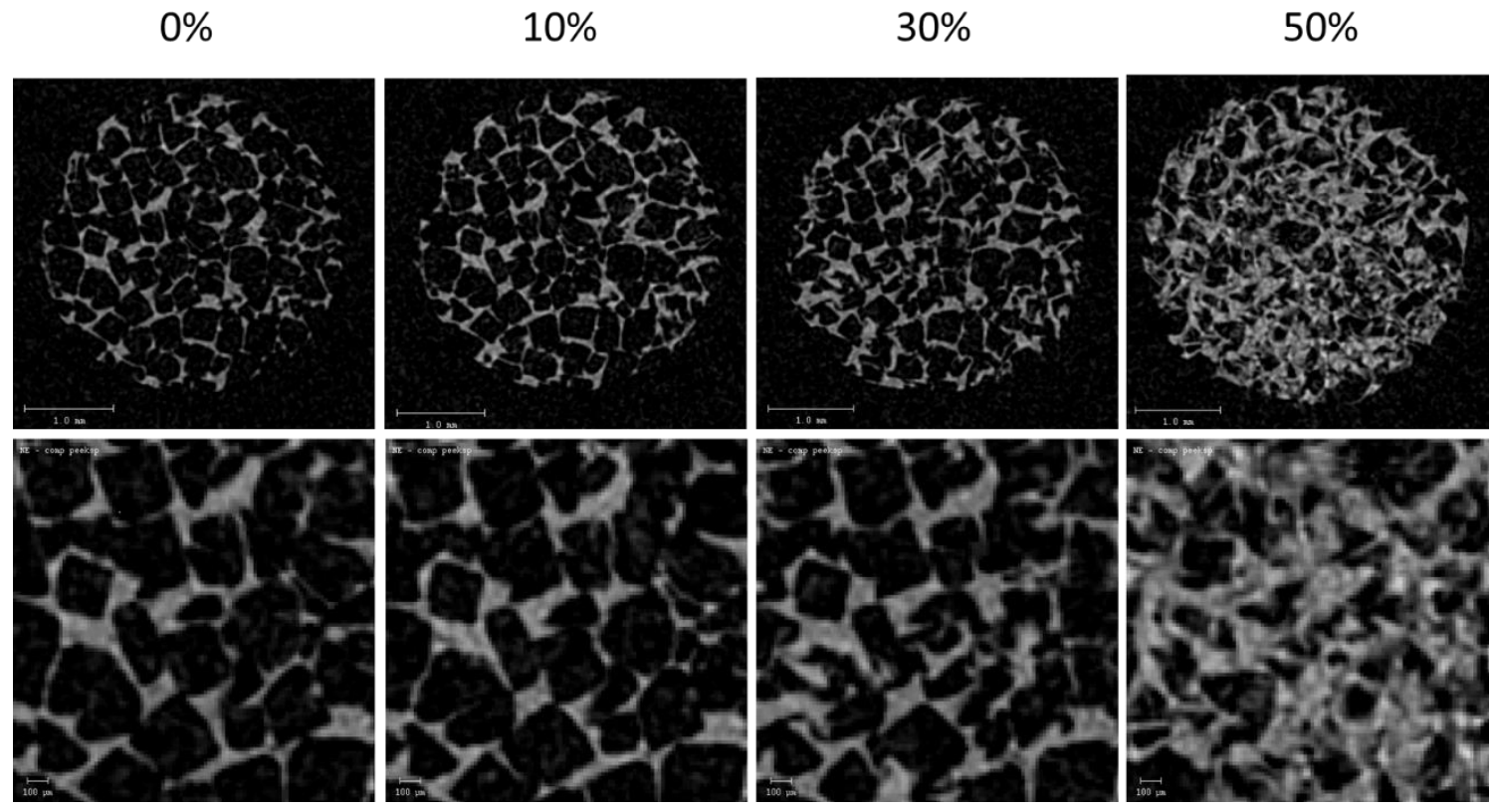

Figure 10. Relationship between the percent porosity and the pore architecture depth.

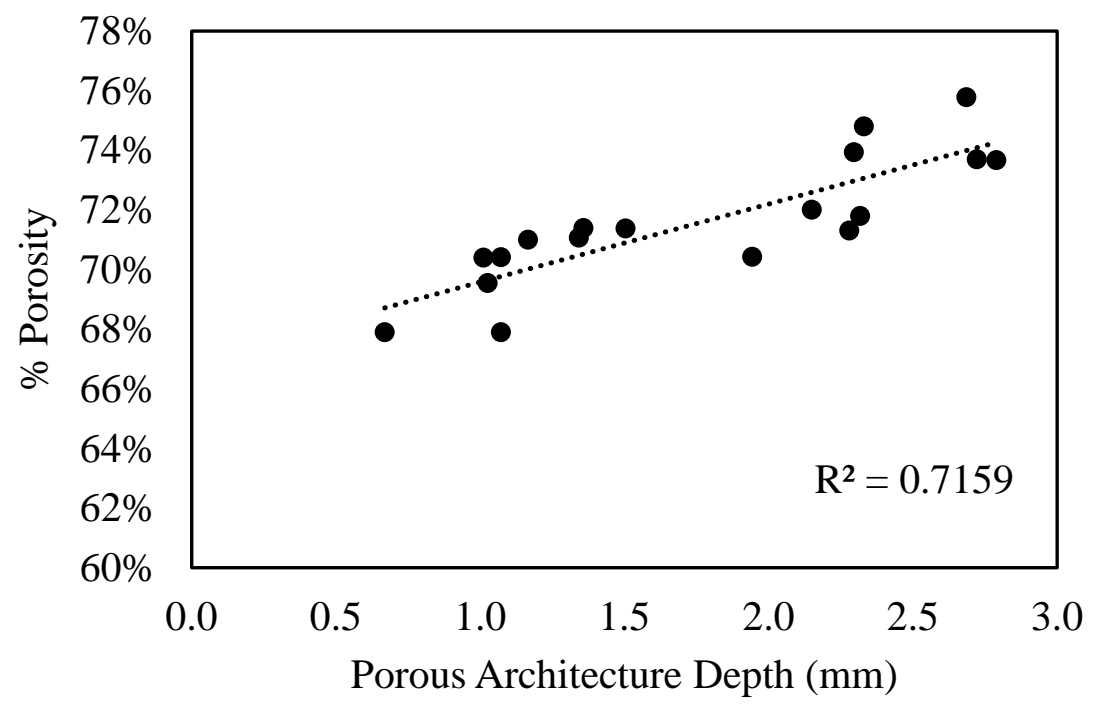


Figure 11. Percent porosity as a function of normalized pore depth for the thinnest pore architecture depth $(0.69 \mathrm{~mm})$ and thickest pore architecture depth $(2.79 \mathrm{~mm})$. Region $\mathbf{a}$ is the pore-air interface, transitioning from $100 \%$ porosity (top, open surface) to the porous region. Region $\mathbf{b}$ is the within the porous architecture, and region $\mathbf{c}$ is the pore-solid interface, transitioning from porous material to $100 \%$ solid material.

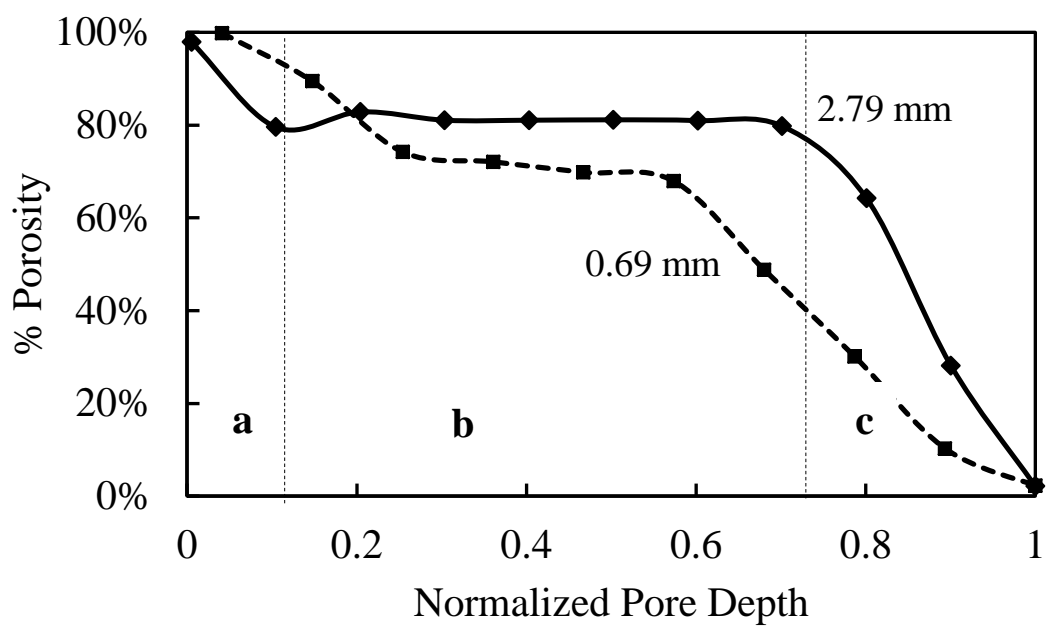

